\title{
AGRICULTURA DE PRECISÃO: PARTICULARIDADES DE SUA ADOÇÃO NO SUDOESTE DE GOIÁS - BRASIL
}

Doi:http://dx.doi.org/10.1590/1809-4430-Eng.Agric.v35n4p 689-698/2015

\section{ROMEU SOARES FILHO', JOÃO P. A. R. DA CUNHA ${ }^{2}$}

RESUMO: A agricultura de precisão tem nos solos do Cerrado Brasileiro um perfeito campo para seu desenvolvimento. Há, entretanto, na região, carência de informações sobre o estado da arte desta nova técnica, já em uso por alguns produtores rurais. Com isso, objetiva-se com este trabalho realizar a análise da adoção e da utilização desta tecnologia na região sudoeste do Estado de Goiás, com informações reais da intensidade e da forma de uso e das condicionantes de sua adoção. Para tanto, foi aplicado um questionário a produtores que utilizavam de alguma forma a agricultura de precisão, analisando os problemas enfrentados com a tecnologia, as fontes de informação e as dificuldades encontradas pelos produtores. Para amostragem, foi utilizado o método não probabilístico, uma vez que a população não era conhecida. Os dados foram submetidos à análise estatística descritiva; e os resultados, apresentados na forma de gráficos. A técnica de agricultura de precisão na região está em fase inicial de adoção. Tem-se na amostragem do solo em grade e adubação a lanço, em taxa variada, as tecnologias mais empregadas. $\mathrm{O}$ uso de sensores e a irrigação de precisão são tecnologias ainda ausentes. Os principais obstáculos são carência de mão de obra especializada e elevados custos dos equipamentos.

PALAVRAS-CHAVE: tecnologia agropecuária, mecanização agrícola, distribuidores a lanço.

\section{PRECISION FARMING: CHARACTERISTICS OF ITS ADOPTION IN THE SOUTHWEST REGION OF GOIÁS - BRAZIL}

\begin{abstract}
Brazilian Cerrado is a perfect region to develop precision agriculture. However, there is a lack of information about the state of the art of this new technique, already in use by some farmers in this region. Therefore, the aim of this study was to make an analysis of the adoption and use of this technology in the southwest region of the state of Goiás, with real information on the intensity and form of usage and limitations of its adoption. For this purpose, a questionnaire was given to the farmers who used some form of precision agriculture, analyzing the problems encountered with the technology, sources of information and the difficulties encountered by them. It was used a non-probabilistic sampling method. Data were subjected to descriptive statistical analysis and the results presented as graphs. The technique of precision agriculture in the analyzed region is in initial adoption phase. The most used technologies are soil sampling grid and distribution of fertilizer in variable rate. The use of sensors and precision irrigation technologies are not being adopted yet. The main obstacles are lack of specialized employees and high costs of equipment.
\end{abstract}

KEYWORDS : agricultural technology, agricultural mechanization, broadcast fertilizer.

\section{INTRODUÇÃO}

A agricultura tem passado por uma série de transformações, tornando-se uma atividade que requer cada vez mais o gerenciamento de seus processos produtivos. $\mathrm{O}$ crescente desenvolvimento de novas técnicas ligadas ao manejo das culturas, novos equipamentos e insumos mais eficientes têm proporcionado ganhos significativos no rendimento das culturas. A viabilidade desta atividade

\footnotetext{
${ }^{1}$ Eng $^{\circ}$ Agrônomo, Doutor, Agência Goiana de Assistência Técnica, Extensão Rural e Pesquisa Agropecuária, EMATER-GO, Rio Verde-GO, Fone: (64) 3621-0640, romeusoares@ibest.com.br

${ }^{2}$ Eng $^{\circ}$ Agrícola, Prof. Doutor, Instituto de Ciências A grárias, UFU, Uberlândia-MG, jpcunha@ iciag.ufu.br 
está sempre em risco em decorrência de fatores controláveis e não controláveis que definem a produtividade agrícola.

O termo agricultura de precisão (AP) é relativamente novo entre os produtores rurais brasileiros e tem gerado dúvidas na utilização de suas técnicas de manejo. Vários são os produtores que associam a AP como um pacote de metodologias que poderá solucionar todos os problemas da agricultura nacional (MOLIN et al., 2010).

O sistema de agricultura de precisão implica a análise da variabilidade espacial, sendo caracterizado pelas etapas de coleta de dados, gerenciamento da informação, aplicação de insumos a taxa variada e, por fim, a avaliação econômica e ambiental dos resultados. Coletar dados significa quantificar a variabilidade existente e identificar sua localização no campo, tanto na produtividade dos cultivos como nos fatores que influenciam na produção. Os dados obtidos são processados e plotados em mapas (MOLIN, 2002). A partir daí, buscam-se as relações de causa e efeito entre a produção e os fatores, propõem-se estratégias de gerenciamento e faz-se a aplicação localizada dos insumos e das práticas, visando à correção das anormalidades verificadas (COELHO, 2005; BARBIERI et al., 2008).

As informações detalhadas das características do solo podem ser obtidas a partir da amostragem intensiva por meio de uma malha amostral e posterior análise laboratorial (RODRIGUES et al., 2012; SANTI et al., 2012) ou diagnosticada atra vés de sensores, entre os quais se destacam os medidores de condutividade elétrica e os sensores de índices de vegetação. Esses índices podem ser utilizados, como referência, na adubação das culturas e no manejo de plantas daninhas (MEROTTO et al., 2012).

A região sudoeste de Goiás destaca-se nacionalmente como polo de desenvolvimento do agronegócio, constituindo um exemplo das transformações ocorridas no setor agropecuário brasileiro. Com a produção de 4,126 milhões de toneladas anuais de milho e soja numa área cultivada de 1.227.118 ha, o sudoeste de Goiás é a maior região produtora destes grãos no Estado, com 38,4\% e 51,6\%, respectivamente, da produção total (BRASIL, 2012). Tal magnitude fortalece o elo da cadeia produtiva de suínos e aves, que tem aproveitado essa eficiência produtiva, levando a região a se inserir no comércio internacional com produtos de maior valor agre gado.

A região iniciou a adoção dos princípios da agricultura de precisão em meados da década de 2000. Com o decorrer do processo, muitas dificuldades foram superadas, mas, atualmente, mesmo sabendo de sua utilização por alguns produtores, não se têm muitas informações da intensidade de seu uso e das condicionantes da adoção desta tecnologia.

A fim de se obter o diagnóstico do estado da arte da agricultura de precisão na região, foram utilizados questionários aplicados aos produtores que, de alguma forma, utilizam esta ferramenta. $\mathrm{O}$ uso de questionários com o objetivo de colher informações acerca da AP vem sendo feito nos Estados Unidos desde 1996, através de uma parceria entre a Crop Life Magazine e a Purdue University's Center for Food and Agricultural Business, onde os formulários são enviados via correios aos revendedores de máquinas e equipamentos ligados à AP (HOLLAND et al., 2013). Ainda de acordo com os autores, dentre os 2.500 questionários enviados, a taxa de resposta variou de 900 (38\%) em 1996 até 171 questionários (6,8\%) em 2013, época da 16 versão. Nos questionários, os pesquisadores indagam acerca do uso de tecnologias de precisão e também das implicações econômicas com seu uso.

Desta forma, objetiva-se com o presente trabalho analisar o processo de adoção e de uso das tecnologias de agricultura de precisão por produtores rurais do sudoeste do Estado de Goiás.

\section{MATERIAL E MÉTODOS}

O sudoeste de Goiás é uma das microrregiões do Estado brasileiro de Goiás, pertencente à mesorregião sul goiana. A região está compreendida entre os paralelos $16^{\circ} 27^{\prime}$ e $19^{\circ} 15^{\prime}$ ' de latitude sul e os meridianos $53^{\circ} 12^{\prime}$ e $50^{\circ} 12^{\prime}$ de longitude oeste de Greenwich. Sua população foi estimada em 494.619 e está dividida em 18 municípios, com área total de 56.111,526 km² (BRASIL, 2012). 
Os quatro municípios mais importantes da região, Rio Verde, Jataí, Mineiros e Montividiu, têm população rural estimada em 26.517 habitantes, e o número de propriedades rurais soma 5.203 unidades (BRASIL, 2010). O agronegócio é a principal atividade econômica da região, destacando-se no cenário nacional como grande produtora de cereais, fibras e cana-de-açúcar.

A amostragem foi feita pelo método não probabilístico. $O$ uso do método não probabilístico deu-se em virtude de a população não estar disponível para ser sorteada, e a seleção dos elementos da amostra foi dependente em parte do julgamento do pesquisador. A etapa inicial da pesquisa consistiu na identificação dos produtores que utilizavam AP. Esta identificação foi feita por meio de contatos com empresas de assistência técnica e extensão rural, cooperativas e indicações dos próprios produtores entrevistados. Todos os questionários foram respondidos por produtores rurais que praticavam, em algum grau, a agricultura de precisão.

Metodologia semelhante já foi empregada anteriormente nos Estados Unidos. Em estudos de adoção de tecnologias de agricultura de precisão, PAXTON et al. (2011) obtiveram dados a partir da resposta de questionários enviados pelos correios a produtores de algodão no Sudeste do País. Para o contacto, utilizou-se de uma lista de potenciais produtores obtida junto ao conselho de algodão em Memphis, Tennessee. WINTEAD et al. (2010), em estudo da adoção de tecnologias de AP por produtores rurais no estado de Alabama - USA, obtiveram dados a partir de questionários preenchidos durante a Conferência de Agricultura de Precisão, em 2009, em Atmore, Alabama.

No presente trabalho, foram utilizados dados primários oriundos de questionários aplicados a produtores de grãos na região sudoeste de Goiás, no período de julho de 2012 a julho de 2013. Os questionários, ferramentas de investigação, com o objetivo de recolher informações acerca do tema seguiram as propostas de AMARO et al. (2005). Na oportunidade, foram obtidas informações de 43 produtores. O questionário seguiu uma sequência lógica de perguntas que possibilitassem ao produtor um entendimento do objetivo do trabalho proposto. As perguntas evoluíam no grau de complexidade. A primeira parte do questionário visava a identificar as características básicas do produtor em termos de gestão da empresa e das culturas exploradas. A segunda parte do questionário objetivava o conhecimento das particularidades na adoção da AP, a partir de quais tecnologias eram usadas na propriedade rural. Na parte final, objetivava as inferências na adoção da AP através de impactos positivos e negativos, e o conhecimento das normas de padronização de comunicação entre tratores e semeadoras, pulverizadores, distribuidores de adubos e corretivos, escarificadores, etc. (ISOBUS). Neste item, também foram diagnosticadas as fontes de informação acerca da AP usada pelos produtores e a importância dos problemas e obstáculos na adoção da nova técnica de gerenciamento da atividade rural. O questionário constou de perguntas abertas e fechadas (múltipla escolha).

Os dados foram tabulados, e a eles foi aplicada estatística descritiva, com a confecção de gráficos.

\section{RESULTADOS E DISCUSSÃO}

O número de produtores que responderam ao questionário foi de 43 , número considerado satisfatório, em vista do universo de produtores que praticam AP na região e pela área pesquisada que foi de 83.161 ha. Considerando a área total cultivada na região em cerca de 1.500 .000 ha (BRASIL, 2012), a área com AP pesquisada equivale a 6,67\%. Todas as propriedades pesquisadas são gerenciadas por seus proprietários e familiares. Destes proprietários rurais, 93,18\% participam de alguma forma de associação, sendo a cooperativa o tipo de associação mais importante, com $92,68 \%$ do total. Além da cooperativa, muitos produtores pertencem também a outras associações para comercialização em conjunto e a sindicatos rurais.

Dentre as culturas nas quais os agricultores utilizam a AP, verificou-se que $100 \%$ dos entrevistados utilizam a cultura da soja em virtude da grande importância desta leguminosa no contexto da agricultura brasileira. Além da soja, a agricultura de precisão é também usada nas culturas de milho $(90,9 \%)$, sorgo e feijão $(9,09 \%)$, que, como são culturas extensivas, respondem às inovações com aumento de produtividade e renda. As culturas produtoras de grãos foram as 
primeiras a terem o enfoque da $\mathrm{AP}$, principalmente pela extensão da área que ocupam na região sudoeste de Goiás; porém, em outras regiões do País, existe o desenvolvimento de estudos para outras espécies, a exemplo de café (FERRAZ et al., 2012), cana-de-açúcar (DEMATTÊ et al., 2014) e frutíferas em geral (KONOPATZKI et al., 2012).

Com relação ao tamanho da área cultivada pelos produtores pesquisados no presente estudo, observou-se que $88,64 \%$ dos produtores que utilizam a AP exploram área superior a 200 ha.

Na Figura 1, é mostrada a taxa de adoção das diferentes tecnologias da AP, e evidencia que a tecnologia de amostragem de solo em grade, procedimento inicial na adoção da AP na região, é feita por $97,73 \%$ dos entrevistados. $\mathrm{Na}$ amostragem do solo em grade, processo de mapeamento das características químicas, o tamanho de cada célula depende do atributo a ser analisado, variando de uma amostra por hectare para fósforo, potássio e saturação de bases, até uma amostra para cada três hectares no caso de determinação da argila (CAON \& GENU, 2013; NANNI et al., 2011). Percebe-se, neste caso, a diferença em relação aos EUA, em que a amostragem do solo é feita baseada em zonas de manejo, mapas de produtividade ou na condutividade elétrica do solo (HOLLAND et al., 2013). No Brasil, no Estado de São Paulo, a amostragem do solo em grade com auxílio de GPS é feita por $31 \%$ dos produtores da indústria sucroalcooleira entrevistados (CIRANI \& MORAES, 2010).

A aplicação de insumos a lanço, em taxa variada ou não, é feita por 90,91\% dos produtores (Figura 1). A prática de distribuir insumos utilizando-se da força centrífuga, a lanço, antes do período de semeio é procedimento comum na região. Com isso, tem-se, no período de semeadura, apenas a distribuição das sementes, operação que é feita mais rapidamente, ganhando-se com isso tempo que será utilizado posteriormente no semeio de milho em segunda safra, após a colheita da safra de verão, comumente chamada de safrinha.

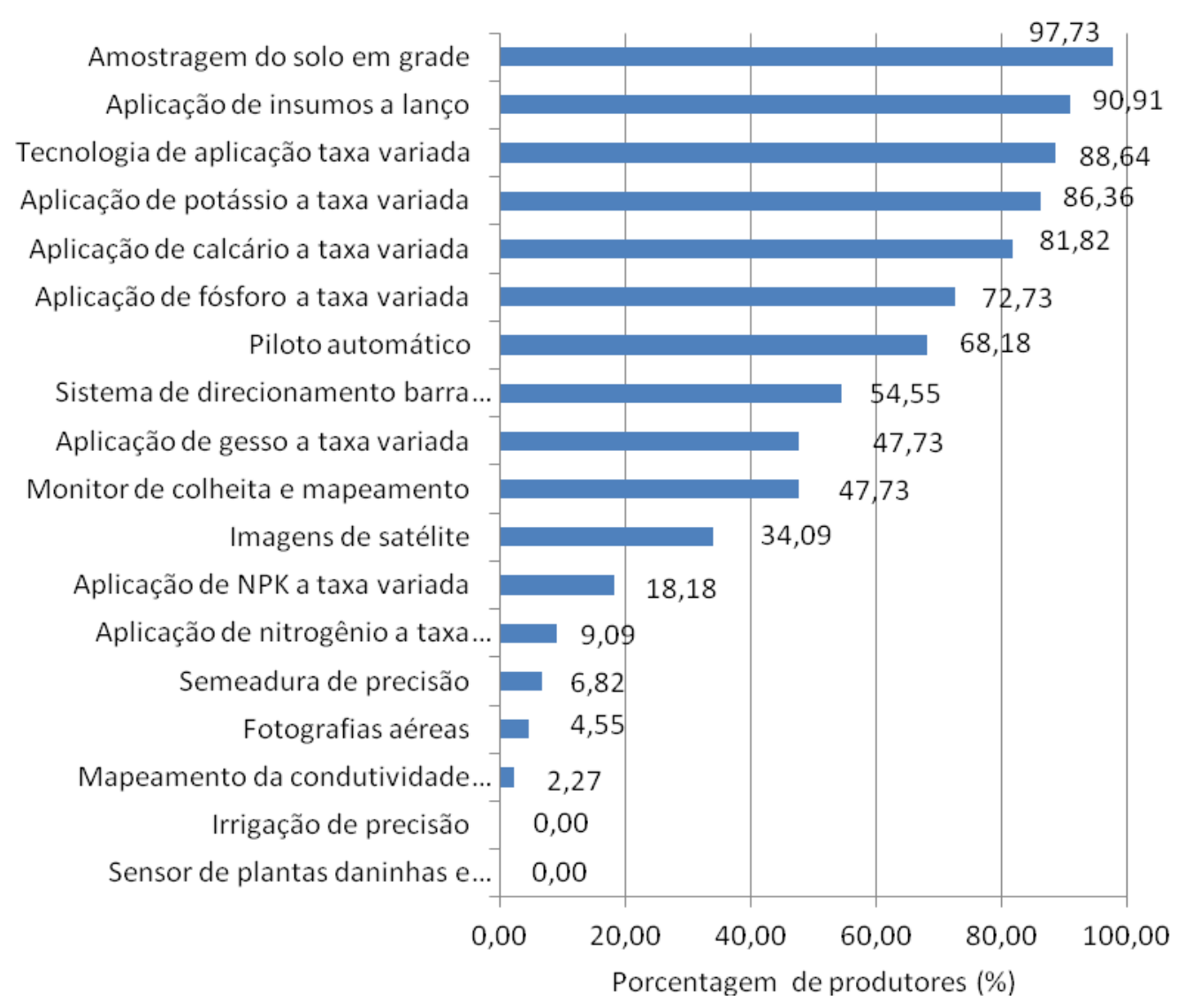

FIGURA 1. Taxa de adoção (\%) das tecnologias de agricultura de precisão pelos produtores pesquisados na região sudoeste de Goiás. Adoption rate (\%) of precision agriculture technology by farmers in the Southwest region of Goiás. 
Verifica-se ainda que a aplicação de insumos a taxa variada, principalmente para potássio e calcário, utilizando distribuidores mecanizados orientados por satélites, tem grande adoção, com $86,36 \%$ e $81,82 \%$, respectivamente (Figura 1). O uso da distribuição de fertilizantes e de corretivos a taxa variada é maior do que a empregada no Alabama (EUA), que em 2009 apresentou, de acordo com WINSTEAD et al. (2010), a utilização de $80 \%$ na aplicação de calcário. Na Austrália, de acordo com ROBERTSON et al. (2011), o nível de adoção de tecnologias, como o mapeamento do rendimento e a aplicação a taxa variável de fertilizantes pelos produtores de grãos, é baixa, em cerca de $20 \%$.

Sistemas de direcionamento por GPS, tanto manual por meio do uso de barra de luz, como por piloto automático, juntamente com a amostragem do solo em grade têm sido as bases na tecnologia da AP. No caso em pauta, 68,18\% dos produtores entrevistados utilizam piloto automático, e $54,55 \%$ têm no sistema de barra de luz o guia na aplicação de insumos em suas propriedades, evidenciando o bom nível tecnológico dos produtores da região. De acordo com BAIO \& MORATELI (2011), o alinhamento das linhas de plantio na cultura da cana-de-açúcar, utilizando piloto automático, alcança a precisão de $0,033 \mathrm{~m}$ entre as passadas, o que proporciona cinco vezes mais acurácia do que o plantio com direcionamento manual. No caso do uso de piloto automático nas culturas de soja e milho na re gião, há melhor distribuição das linhas de plantio otimizando o uso da área, facilitando os tratos culturais e a colheita. De acordo com HOLLAND et al. (2013), nos EUA, o uso de piloto automático está presente em $82 \%$ das propriedades que utilizam AP, e 44\% utilizam tanto o piloto automático como o sistema de barra de luz. Isto se deve, provavelmente, devido a equipamentos com diferentes conformações; por exemplo, no plantio, utiliza-se de piloto auto mático e na aplicação de agrotóxicos usa-se a barra de luz.

Com relação às ferramentas de diagnóstico agronômico, observa-se, na região, que o mapa de produtividade, que representa a variabilidade espacial de uma área cultivada, obtido com o uso de monitor de colheita e imagens de satélite, mesmo sendo ferramenta usada para representar a variabilidade espacial das características de uma área cultivada (SPEZIA et al., 2012; ZANZARINI et al., 2013) não está, ainda, sendo plenamente aproveitado por produtores da região, sendo utilizado por $47,73 \%$ e $34,09 \%$, respectivamente. A condutividade elétrica do solo está relacionada com sua textura e umidade atual, e a partir de sua determinação, podem-se estimar a variação granulométrica e o teor de água deste solo (MOLIN \& RABELLO, 2011). Na região, em apenas 2,27\% dos produtores entrevistados, foi observado o uso desta ferramenta de AP. De modo similar, o uso de sensores de plantas infestantes e doenças não foi citado por nenhum produtor. Isto se deve ao grau inicial da utilização das tecnologias de AP na região, ao alto custo, à deficiência das tec nologias existentes e à pouca difusão destas ferramentas de diagnóstico agronômico.

Os resultados da pesquisa evidenciam que a tecnologia de AP aind a tem muito a crescer, evidentemente com a resolução dos problemas com que a prática convive atualmente, por exemplo, a falta de mão de obra especializada, altos custos de implantação e falta de compatibilidade entre os aplicativos computacionais e as máquinas e equipamentos. $\mathrm{Na}$ medida em que as limitações tecnológicas forem superadas, espera-se que maior número de produtores adote a prática de AP e com maior abrangência, possibilitando o crescimento da atividade agrícola como um todo.

O tempo médio de utilização das tecnologias de AP é de 3,4 anos, variando de 1 a 10 anos, sendo que $72,73 \%$ dos produtores que se utilizam da técnica têm até quatro anos de utilização. Em vista disso, temos a AP em fase de consolidação, e, como qualquer tecnologia, a fase de implantação demanda ajustes e grande treinamento por parte dos usuários. Mesmo estando no estágio inicial, é pretensão de 68,18\% dos entrevistados expandirem sua utilização.

O emprego das tecnologias de AP demanda assistência técnica especializada, que é co ntratada por $88,06 \%$ dos produtores entrevistados, e maquinário agrícola, que em 95,46\% dos produtores é próprio. No caso de aquisições recentes, 90,90\% dos entrevistados afirmaram que há necessidade de máquinas projetadas para o trabalho com $\mathrm{AP}$, de forma a evitar as adaptações em equipamentos não adequados para esta tecnologia. 
Sobre a qualificação de mão de obra para as atividades de AP na propriedade rural, $56,82 \%$ dos produtores, ao serem questionados sobre a preparação da mão de obra, responderam que não fizeram treinamento de seus colaboradores especificamente para as práticas de AP. Os outros 43,18\% afirmaram que proporcionaram aos seus trabalhadores treinamento específico. Normalmente, o treinamento é dado pelos fabricantes e concessionárias das máquinas e equipamentos comercializados aos produtores rurais. $\mathrm{Na} \mathrm{AP}$, utilizam-se máquinas com muita tecnologia embarcada, necessitando de conhecimentos específicos voltados para a informática e a eletrônica. De acordo com BIANCHETTI (2001), esse novo contexto exige da classe trabalhadora um novo perfil para exercer suas atividades por causa da exigência das novas tecnologias que priorizam o trabalho abstrato. Segundo o autor, em um espaço de tempo curto, a força de trabalho deve adequar-se aos novos e crescentes desafios da reestruturação produtiva, seja em seus aspectos tecnológicos, seja nos de gestão.

O impacto da AP no aumento da produtividade foi considerado grande ou médio por 70,23\% dos entrevistados, porém com relação à redução dos custos de produção, para 50\% dos produtores, este impacto é pequeno ou inexistente. Segundo eles, a diminuição do uso de insumos em uma gleba é compensada com o aumento da quantidade necessária em outras glebas, mantendo os custos constantes.

Segundo 68,18\% dos produtores pesquisados, a AP promove a redução dos impactos ambientais com o uso mais racional de insumos.

O protocolo universal para comunicação eletrônica entre implementos, tratores e computadores, normalmente denominado de ISOBUS, tem como base a norma internacional ISO 11783 ("Tratores e máquinas agrícolas e florestais - Rede serial para controle e comunicação de dados") e tem como objetivo padronizar a comunicação estabelecida entre tratores e implementos, ao mesmo tempo em que assegura a compatibilidade total de transferência de dados entre sistemas móveis e software (FTI BRASIL, 2011). Devido ao fato de produtores geralmente utilizarem tratores e implementos de fornecedores diferentes, também são diferentes os sistemas eletrônicos, e para cada conjunto de trator/equipamento, pode ser necessário um terminal individual. Dos produtores pesquisados $81,82 \%$ declararam não conhecer este protocolo, mostrando a falta de informações que chegam ao campo.

Considerando as fontes de informação disponíveis aos produtores da região (Figura 2), dentre elas as mais importantes são as empresas de consultoria agropecuária, que assistem o produtor na condução de suas lavouras e, a seguir, as feiras e exposições na região.

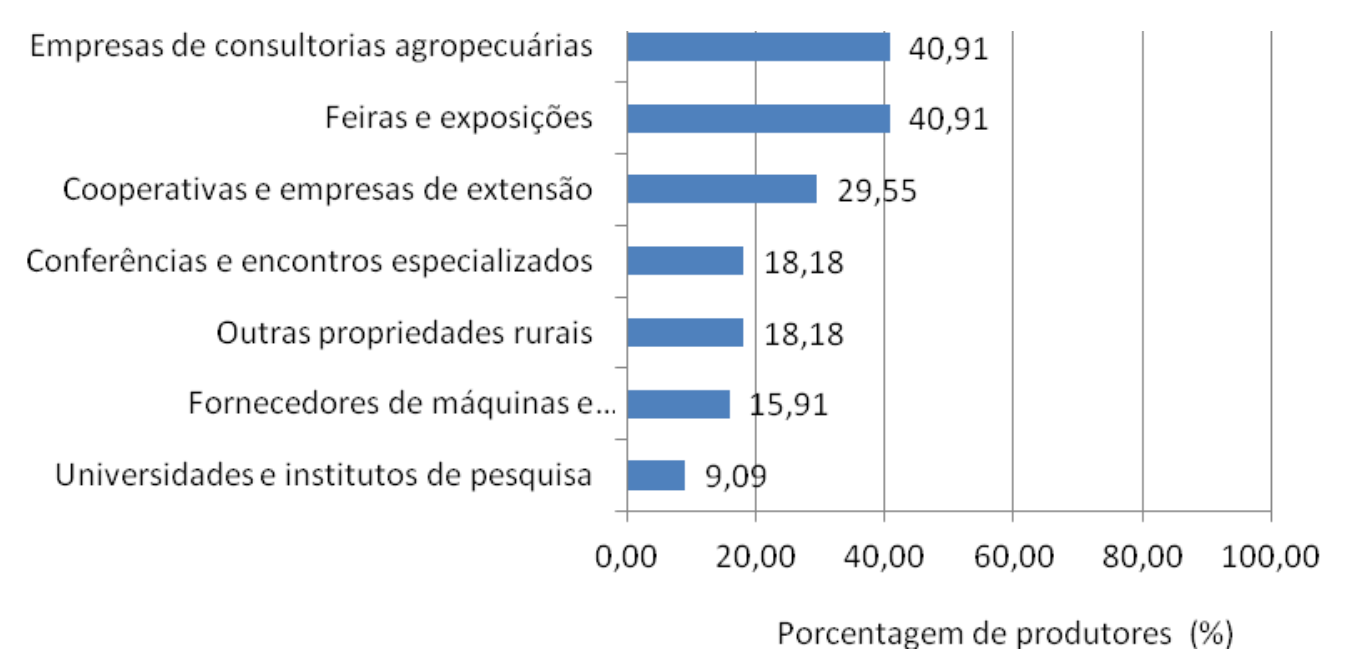

FIGURA 2. Fontes de informação consideradas de alta importância na adoção de agricultura de precisão pelos produtores (\%) da região sudoeste de Goiás. Information sources considered highly important in the adoption by precision agriculture users $(\%)$ from Southwest Goiás region. 
Por outro lado, a pesquisa mostra que apenas $9,09 \%$ dos produtores pesquisados consideram as universidades e os centros de pesquisa fonte de alta importância na difusão das técnicas de AP. A região possui quatro importantes instituições de ensino superior em ciências agrárias e isto demonstra a pouca importância dada à difusão de tecnologia e extensão rural por estes centros de conhecimento. De acordo com BRAMLEY \& TRENGOVE (2013), na Austrália, a formação de grupos de produtores foi a alternativa encontrada para promover a adoção e o desenvolvimento da AP. Como exemplo destes grupos, os autores citam o SPAA (Precison Agriculture Australia), que facilita a pesquisa e a extensão visando a melhorar a rentabilidade e a sustentabilidade dos sistemas agrícolas.

Com relação aos problemas e aos obstáculos sentidos pelos produtores na adoção da AP, verifica-se que a falta de pessoal qualificado e os altos custos da tecnologia de AP são os maiores obstáculos na opinião dos produtores (Figura 3). De acordo com COELHO (2008), os altos custos da tecnologia tendem a diminuir com o tempo com o maior número de produtores adotando a técnica, aliado à rápida evolução tecnológica. A falta de mão de obra qualificada para atuar na área de AP pode ser solucionada através de parcerias com instituições de ensino, pesquisa e extensão rural, com o objetivo de qualificar pessoal, haja vista a complexidade da atividade. A aquisição de novas máquinas e equipamentos, considerada por $40,91 \%$ dos produtores entrevistados como obstáculo de alta importância na adoção das tecnologias da AP, ocorre pelo custo de aquisição e de manutenção, além da necessidade da compatibilidade entre as diversas máquinas e equipamentos da propriedade.

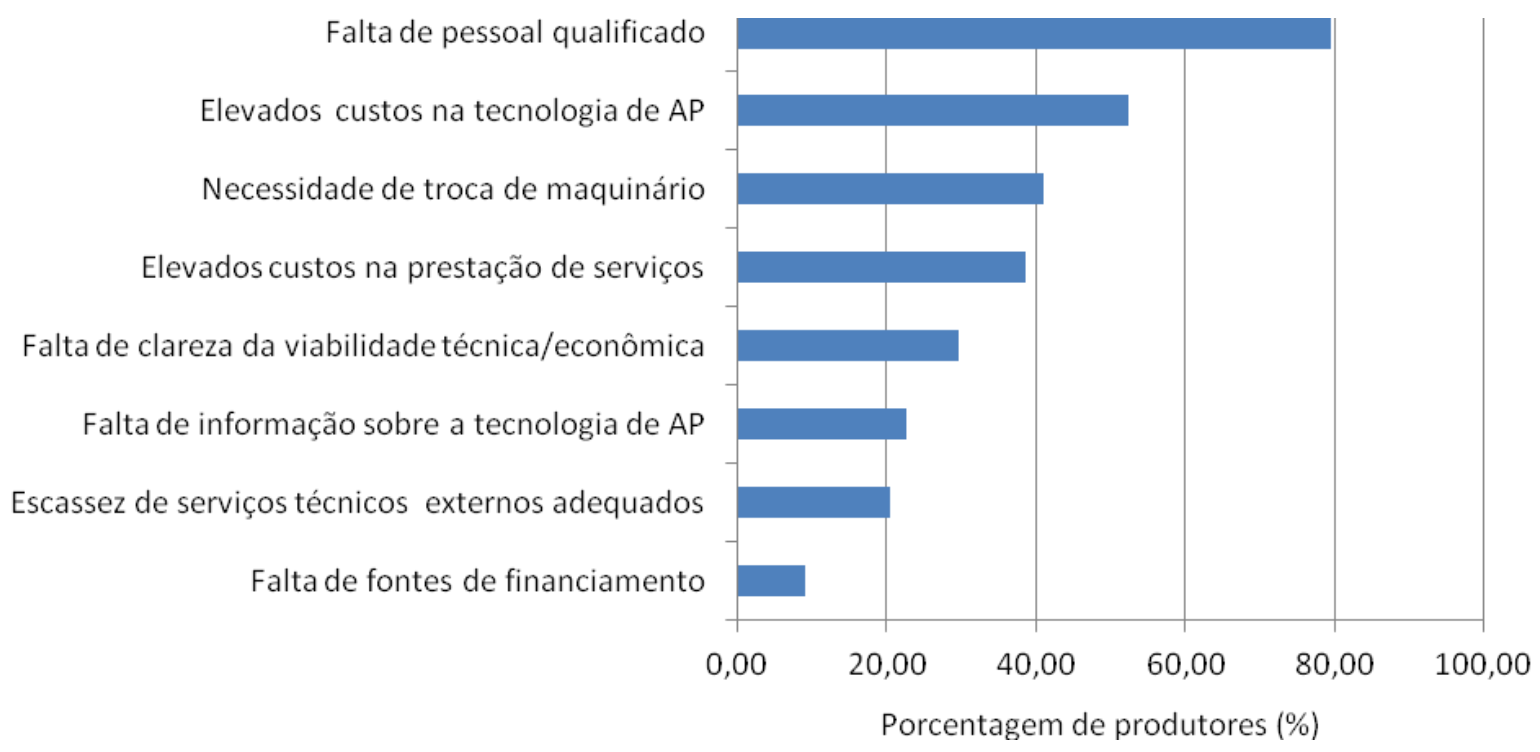

FIGURA 3. Problemas e obstáculos na adoção da agricultura de precisão considerados de alta importância pelos produtores (\%) da região sudoeste de Goiás. Problems and barriers to adoption of precision agriculture considered highly important by farme rs $(\%)$ from Southwest region of Goiás.

\section{CONCLUSÕES}

Considerando os parâmetros avaliados, pôde-se concluir que a técnica de AP no sudoeste do Estado de Goiás está em fase inicial de adoção.

A amostragem de solo em grade e a adubação a taxa variada a lanço são as tecnologias de AP mais empregadas. Uso de sensores agronômicos e irrigação de precisão são tecnologias ainda ausentes. Medição da condutividade elétrica do solo e uso de fotografias aéreas são tecnologias de ponta que ainda estão muito incipientes. 
As principais fontes de informação sobre AP são as empresas de consultoria agropecuária e as feiras e exposições da região. Os principais obstáculos apontados como entraves no uso da tecnologia foram carência de mão de obra especializada e elevados custos dos equipamentos de AP. Contudo, os produtores afirmaram que pretendem expandir a utilização das técnicas de AP.

\section{REFERÊNCIAS}

AMARO, A.; PÓVOA, A.; MACEDO, L. A arte de fazer questionários. Porto: Faculdade de Ciências da Universidade do Porto, Departamento de Química, Metodologias de Investigação em Educação. Disponível em: <http://www. jcpaiva. net/getfile. php, 2005>. Acesso em: 15 dez. 2011.

BAIO, F. H. R.; MORATELLI, R. F. Avaliação da acurácia no direcionamento com piloto automático e contraste da capacidade de campo operacional no plantio mecanizado da cana-deaçúcar. Engenharia Agrícola, Jaboticabal, v. 31, n. 2, abr. 2011. Disponível em <http://www.scielo.br/scielo.php?script=sci_arttext\&pid=S0100>. Acesso em: 26 maio 2014.

BARBIERI, D. M.; MARQUES JÚNIOR, J.; PEREIRA, G. T. Variabilidade espacial de atributos químicos de um Argissolo para aplicação de insumos à taxa variável em diferentes formas de relevo. Engenharia Agrícola, Jaboticabal, v. 28, p. 645-653, out./dez. 2008.

Disponível em: <http://www.scielo.br/pdf/eagri/v28n4/04.pdf>. Acesso em: 1o jul. 2014.

BIANCHETTI, R. G. Modelo neoliberal e políticas educacionais. 3. ed. São Paulo: Cortez, 2001.

BRAMLEY, R.; TRENGOVE, S. Precision agriculture in Australia:present status and recent developments. Engenharia Agrícola, Jaboticabal, v. 33, n. 3, jun. 2013. Disponível em:

$<$ http://www.scielo.br/scielo.php?script=sci_arttext\&pid=S0100-69162013000300014\&lng=pt\&nrm=iso $>$. Acesso em: 27 maio 2014.

BRASIL. Ministério do Planejamento, Orçamento e Gestão. Instituto Brasileiro de Geografia e Estatística, 2012. Disponível em: <http://www.ibge.gov.br/estadosat/perfil.php?sigla=go\#>. Acesso em: 15 out. 2014.

BRASIL. Ministério do Planejamento, Orçamento e Gestão. Instituto Brasileiro de Geografia e estatística. Censo 2010 - Sinopse do censo demográfico 2010 - Goiás. Disponível em:

<www.censo2010.ibge. go v.br/sinopse/index.php?dados=29\&uf=52>. Acesso em: 10 nov. 2014.

CAON, D.; GENÚ, A. M. Mapeamento de atributos químicos em diferentes densidades amostrais e influência na adubação e calagem. Revista Brasileira de Engenharia Agrícola e Ambiental, Campina Grande, v. 17, n. 6, p. 629-639, 2013. Disponível em:

<http://www.scielo.br/pdf/rbeaa/v17n6/v17n6a09.pdf>. Acesso em: 20 ago. 2014.

CIRANI, C. B. S.; MORAES, M. A. F. D. de. Inovação na indústria sucroalcooleira paulista: os determinantes da adoção das tecnologias de agricultura de precisão. Revista de Economia e

Sociologia Rural, v. 48, n. 4, p. 543-565, 2010. Disponível em:

$<$ http://www.scielo.br/scielo.php?script=sci_arttext\&pid=S0103-

$20032010000400003 \& \operatorname{lng}=$ en\&nrm=iso>. Acesso em: 24 maio 2014.

COELHO, A. M. Agricultura de precisão: manejo da variabilidade espaciale temporal dos solos e culturas. Sete Lagoas: Embrapa Milho e Sorgo, 2005. Disponível em:

<http://ainfo.cnptia.embrapa.br/digital/bitstream/CNPMS/18887/1/Doc_46.pdf.> Acesso em: 24 ago. 2014.

COELHO,A. M. Agricultura de precisão em sistemas agrícolas. In: FALEIRO, F.G.; FARIAS NETO, A.L. Savanas: desafios e estratégias para o equilíbrio entre sociedade, agronegócio e recursos naturais. Planaltina, DF: Embrapa Cerrados, 2008. p. 1063-1083. Disponível em: <http://simposio.cpac.embrapa.br/simposio_pc210/projeto/palestras/capitulo_35.pdf.> Acesso em: 20 out. 2014. 
DEMATTÊ, J. A. M.; DEMATTÊ, J. L. I.; ALVES, E. R.; NEGRÃO, R.; MORELLI, J. L. Precision agriculture for sugarcane management: a strategy applied for brazilian conditions. Acta Scientiarum. Agronomy, Maringá, v. 36, n. 1, p. 111-117, jan.-mar. 2014. Disponívelem: $<$ http://www.scielo.br/scielo.php?script=sci_arttext\&pid=S180786212014000100015\&lng=en\&nrm=iso>. Acesso em: 29 Mai 2014.

FERRAZ, G. A. E. S.; SILVA, F. M.; CARVAlHO, L. C. C.; ALVES, M. C.; FRANCO, B. C. Variabilidade espacial e temporal do fósforo, potássio e da produtividade de uma lavoura cafeeira. Engenharia Agrícola, Jaboticabal, v. 32, n. 1, jan./fev. 2012. Disponível em: $<$ http://www.scielo.br/scielo.php?script=sci_artte xt\&pid=S010069162012000100015\&lng=en\&nrm=iso>. Acesso em: 29 maio 2014.

FTI BRASIL - Força Tarefa ISOBUS Brasil. Uma iniciativa para inserir o B rasil no esforço internacional de padronização e comunicação entre tratores e imple mentos agrícolas . 2011.

Disponível em: <http://www.isobus.org.br/ >. Acesso em: 15 maio 2014.

HOLLAND, J. K.; ERICKSON, B.; WIDMAR, D. A. 2013 Precision Agricultural services Dealership Survey Results. Sponsored by Croplife Magazine and Center for Food and Agricultural business. West Lafayette: Dept. of Agricultural Economics, Purdue University, 2013. Disponível em: <http://agribusiness.purdue.edu/files/resources/rs-11-2013-holland-erickson-widmar-dcroplife.pdf $>$. Acesso em: 20 jan. 2014.

KONOPATZKI, M. R. S.; SOUZA, E. G.; NÓBREGA, L. H. P.; URIBE-OPAZO, M. A.; SUSZEK, G. Spatial variability of yield and other parameters associated with pear trees.

Engenharia Agrícola, Jaboticabal, v. 32, n. 2, p. 381-392, mar./apr. 2012. Disponível em: $<$ http://www.scielo.br/scielo.php?script=sci_arttext\&pid=S0100-

69162012000200018\&lng=en\&nrm=iso>. Acesso em: 29 maio 2014.

MEROTTO JR. A.; BREDEMEIER, C.; VIDAL, R. A.; GOULART, I. C. G. R.; BORTOLI, E. D.; ANDERSON, N. L. Reflectance ind ices as a diagnostic tool for weed control performed by multipurpose equipment in precision agriculture. Planta Daninha, Viçosa, MG, v. 30, n. 2, P. 437-447, 2012. Disponível em: <http://www.scielo.br/scielo.php?script=sci_arttext\&pid=S010083582012000200024\&lng=en\&nrm=iso>. Acesso em: 27 maio 2014.

MOLIN, J. P. Desafios da agricultura brasileira a partir da agricultura de precisão. In: SIMPÓSIO SOBRE ROTAÇÃO SOJA/MILHO NO PLANTIO DIRETO, 3., 2002, Piracicaba. Anais... Piracicaba: Potafós, 2002.

MOLIN, J. P; RABELLO, L. M. Estudos sobre a mensuração da condutividade elétrica do solo. Engenharia Agrícola, Jaboticabal, v. 31, n. 1, p. 90-101, jan./fev. 2011. Disponível em: $<$ http://www.scielo.br/scielo.php?script=sci_arttext\&pid=S010069162011000100009\&lng=pt\&nrm=iso >. Acesso em: 27 maio 2014.

MOLIN, J. P.; MOTOMIYA, A. V. A.; FEASSON, F. R., FAULIN, G. G.; TOSTA, W. Test procedure for variable rate fertilizer on coffee. Acta Scientiarum. Agronomy, Maringá, v. 32, n. 4, p. 569-575, 2010. Disponível em: <http://www.scielo.br/scielo.php?pid=S1807-

$86212010000400001 \&$ script=sci_arttext $>$. Acesso em: 25 out 2014.

NANNI, M. R.; POVH, F. P.; DEMATTÊ, J. A. M.; OLIVEIRA, R. B.; CHICATI, M. L.; CEZAR, E. Optimum size in grid soil sampling for variable rate application in site-specific management.

Scientia Agricola, Piracicaba, v. 68, n. 3, p. 386-392, May/June 2011. Disponível em: $<$ http://www.scielo.br/scielo.php?script=sci_arttext\&pid=S0103-

90162011000300017\&lng=en\&nrm=iso>. Acesso em: 26 maio 2014. 
PAXTON, K. W.; MISHRA, A. K.; CHINTAWAR, S.; ROBERTS, R. K.; LARSON, J. A.; ENGLISH, B. C.; LAMBERT, D. M.; MARRA, M. C.; LARKIN, S. L.; REEVES, J. M.; MARTIN, S. W. Intensity of precision agriculture technology adoption by cotton producers. Agricultural and Resource Economics Review, v. 40, n. 1, p. 133-144, 2011. Disponível em: <http://ageconsearch.umn.edu/bitstream/105464/2/mishra\%20-\%20current.pdf >. Acesso em: 10 nov. 2014

ROBERTSON, M.J.; LLEWELLYN, R.S.; MANDEL, R.; LAWES, R.; BRAMLEY, R.G.V.; SWIFT, L.; METZ, N.; O'CALLAGHAN, C. Adoption of variable rate technology in the Australian grains industry: status, issues and prospects. Precision Agriculture, Dordrecth, v. 13, p. 181-199, 2011.

RODRIGUES, M. S.; CORA, J. E.; FERNANDES, C. Soil sampling intensity and spatial distribution pattern of soils attributes and corn yield in no-tillage system. Engenharia Agrícola, Jaboticabal, v. 32, n. 5, p. 852-865, set./out. 2012. Disponível em: $<$ http://www.scielo.br/scielo.php?script=sci_arttext\&pid=S010069162012000500005\&lng=en\&nrm=iso>. Acesso em: 27 maio 2014.

SANTI, A. L.; AMADO, T. J. C.; CHERUBIN, M. R.; MARTIN, T. N.; PIRES, J. L.; DELLA FLORA, L. P.; BASSO, C. J. Análise de componentes principais de atributos químicos e físicos do solo limitantes à produtividade de grãos. Pesquisa Agropecuária B rasileira, Brasília, v. 47, n. 9, set. 2012. Disponível em <http://www.scielo.br/scielo.php?script=sci_arttext\&pid=S0100204X2012000900020\&lng=pt\&nrm=iso>. Acesso em: 28 maio 2014.

SPEZIA, G. R.; SOUZA. E. G.; NÓBREGA, L. H. P.; URIBE-OPAZO, M. A.; MILAN, M.; BAZZI, C. L. Model to estimate the sampling density for establishment of yield mapping. Revista Brasileira de Engenharia Agrícola e Ambiental, Campina Grande, v. 16, n. 4, p. 449-457, Apr. 2012. Disponível em: <http://www.scielo.br/scielo.php?script=sci_arttext\&pid=S141543662012000400016\&lng=en\&nrm=iso>. Acesso em: 29 maio 2014.

WINSTEAD, A. T.; NORWOOD, S. H.; GRIFFIN, T. W.; RUNGE, M.; ADRIAN, A. M.; FULTON, J.; KELTON, J. Adoption and use of precision agriculture technologies by practitioners. In: INTERNATIONAL CONFERENCE ON PRECISION AGRICULTURE, 10., 2010, Colorado. Proceedings...

Disponível em: <http://www.aces.edu/anr/precisionag/documents/ICPAAdoptionandUseofPA.pdf $>$. Acesso em: 10 nov. 2014.

ZANZARINI, F.V.; PISS ARRA, T. C. T.; BRANDÃO, F. J. C.; TEIXEIRA, D. D. B. Correlação espacial do índice de vegetação (NDVI) de imagem Landsat/ETM+ com atributos do solo. Revista Brasileira de Engenharia Agrícola e Ambiental, Campina Grande, v. 17, n. 6, 2013. Disponível em: <http://www.scielo.br/scielo.php?script=sci_arttext\&pid=S1415-

$43662013000600006 \& \operatorname{lng}=$ pt\&nrm=iso>. Acesso em: 30 maio 2014. 